\title{
C-reactive protein levels in subjects with Prader-Willi syndrome and obesity
}

\author{
Merlin G. Butler, $\mathrm{MD}, \mathrm{PhD}^{1}$, Douglas C. Bittel, $P h D^{1}$, Nataliya Kibiryeva, $\mathrm{MD}^{1}$, and Uttam Garg, $P h D^{2}$
}

\begin{abstract}
Purpose: Prader-Willi syndrome is characterized by infantile hypotonia, feeding difficulties, hypogonadism, small hands and feet, mental deficiency, behavioral problems, and hyperphagia leading to obesity in early childhood. To date there have been no studies examining the associated risk of cardiovascular disease related to obesity in Prader-Willi syndrome, nor of circulating biomarkers such as C-reactive protein known to be predictive of cardiovascular disease. Therefore, we have measured the levels of C-reactive protein in a descriptive study of a cohort of Prader-Willi syndrome and comparison subjects. Methods: An immunoassay was used to quantify C-reactive protein in plasma samples from subjects with Prader-Willi syndrome and obesity and compared to anthropometric and body composition data. Results: The mean circulating C-reactive protein concentration for 28 subjects with Prader-Willi syndrome (13 females, 15 males; mean age $24.6 \pm 11.6$ years; mean body mass index $35.9 \pm 11.9$ ) was $10.3 \pm 8.8 \mathrm{mg} / \mathrm{L}$. The mean C-reactive protein concentration for 22 nonsyndromic obese subjects (16 females, 6 males; mean age $32.3 \pm 12.2$ years; mean body mass index $36.6 \pm 10.7$ ) was $8.8 \pm 10.9 \mathrm{mg} / \mathrm{L}$. The reported mean value for C-reactive protein was $2.6 \pm 3.0 \mathrm{mg} / \mathrm{L}$ from 100 healthy adults. Conclusions: The mean C-reactive protein values were similar between the subjects with Prader-Willi syndrome and obesity but significantly higher in Prader-Willi syndrome and obese subjects relative to normative data. Increased levels of C-reactive protein $(>3.0 \mathrm{mg} / \mathrm{L}$ ) are associated with cardiovascular disease suggesting subjects with Prader-Willi syndrome as well as obese subjects are at a similar increased risk. Genet Med 2006:8(4):243-248.
\end{abstract}

Key Words: biomarkers, body mass index, cardiovascular disease, C-reactive protein (CRP),

Prader-Willi syndrome (PWS), obesity

C-reactive protein (CRP) is found in serum and binds to the C-polysaccharide of Streptococcus pneumoniae ${ }^{1}$ and is up-regulated during infectious and noninfectious inflammatory responses in humans. ${ }^{2}$ It is highly conserved with a molecular mass of approximately 118,000 D and composed of five identical cyclic globular subunits. ${ }^{3}$ It is classified as a member of the pentraxin superfamily of proteins. ${ }^{3-4} \mathrm{CRP}$ is synthesized in the liver and presents in trace amounts in the serum or plasma in humans with normal individuals having $<3 \mathrm{mg} / \mathrm{L}$. Plasma CRP levels rise during inflammatory conditions such as rheumatoid arthritis and cardiovascular or peripheral vascular diseases. Within 24 to 48 hours following acute tissue damage the production of CRP dramatically increases to approximately 1000 times the constitutive level and may remain elevated for several days before returning to normal. ${ }^{3-5}$

\footnotetext{
From the ${ }^{1}$ Section of Medical Genetics and Molecular Medicine, ${ }^{2}$ Department of Pathology, Children's Mercy Hospitals and Clinics and University of Missouri- Kansas City School of Medicine, Kansas City, MO.

Merlin G. Butler, MD, PhD, Children's Mercy Hospitals and Clinics, Section of Medical Genetics and Molecular Medicine, 2401 Gillham Rd. Kansas City, MO 64108.

Submitted for publication September 28, 2005.

Accepted for publication December 14, 2005.
}

DOI: 10.1097/01.gim.0000204469.30913.67
An elevated CRP level is identified as a predictive marker for cardiovascular disease and also is supplementary to traditional risk factors such as obesity (particularly upper body fatness patterns), smoking, diabetes mellitus, high cholesterol and triglyceride levels and hypertension in both men and women in the general population. ${ }^{6-9}$ There is a correlation between higher body mass index and increased CRP concentrations; ${ }^{10}$ thus, a direct relationship between obesity and CRP levels as well as a relationship between weight loss and a reduction in CRP levels. ${ }^{11,12}$ Twin studies have shown that genetic factors account for as much as $40 \%$ of the variance in plasma CRP levels..$^{13}$ In addition, polymorphisms within the CRP gene promoter region are found to influence plasma CRP levels. ${ }^{14}$

Prader-Willi syndrome (PWS), the most common known genetic cause of life-threatening obesity, is characterized by infantile hypotonia, feeding difficulties, hypogonadism, small hands and feet, mental deficiency, behavioral problems, hyperphagia leading to early childhood obesity and a paternal chromosome 15qll-q13 deletion in the majority of subjects. ${ }^{15-18}$ It was recognized as the first example of genomic imprinting in humans or the differential expression of genetic information depending on the parent of origin. ${ }^{19}$ Whether obesity associated with Prader-Willi syndrome contributes to an increased risk for diabetes and cardiovascular disease is unclear. Individuals with PWS are generally diagnosed earlier now than in the 
past and live longer therefore potentially at risk of developing cardiovascular and obesity related disorders as they become older. Thus, the question of increased risk for obesity related diseases becomes more important with the aging PWS population worldwide.

There are only a few well-documented cases of coronary artery disease reported in PWS. For example, a 26-year-old man with PWS and type 2 diabetes mellitus was reported with a myocardial infarction and inoperable 3-vessel coronary artery disease ${ }^{20}$ and a 28 -year-old woman with PWS was found to have stenosis of the left anterior descending artery with probable myocardial infarction after presenting with chest pain. ${ }^{21}$ There are few reports of atherosclerotic heart disease in PWS, usually as an incidental finding. In addition, there are only scattered reports of cerebrovascular accidents in the PWS population including a report of a teenager with PWS and type 2 diabetes mellitus and a vaso-occlusive stroke with revascularization of the middle cerebral arteries. ${ }^{22}$ Since ischemic vascular disease is commonly linked to obesity in the general population, ${ }^{23-25}$ the low number of reports or prevalence of these conditions in PWS is surprising and may be due to underreporting or perhaps to lower than expected occurrence of dyslipidemia and insulin-resistance, ${ }^{26,27}$ higher adiponectin levels, ${ }^{28,29}$ or lower CRP levels than commonly seen in the general obese population.

Persons with PWS are noted to have growth hormone deficiency (GHD) and the relationship between GHD and dyslipidemia are discussed in a recent article by Hoybye et al. ${ }^{28}$ In addition, a potential direct interaction between CRP and SNRPN (Sm-D) proteins has been reported ${ }^{30,31}$ which may impact on function or levels of gene product. The significance of this observation for PWS is unknown but would likely be similar for subjects with deletion or UPD since both lack expression of the SNRPN gene. However, CRP levels would be expected to be elevated in PWS due to obesity and potential involvement of SNRPN which is an imprinted gene located in the 15qll-q13 region. Therefore, subjects with PWS should have an enhanced risk for cardiovascular disease but no current systematic studies exist confirming an associated risk of heart disease in this patient population nor studies on predictive circulating biomarkers such as CRP.

These observations and expectations led to our rationale to perform a descriptive study in comparing CRP levels in subjects with PWS and obesity. We obtained fasting plasma CRP levels in a cohort of mostly adult PWS and obese subjects using commercially available immunoassays and characterized the levels in relationship to anthropometric and body compositions measures. To our knowledge this is the first report to measure plasma CRP levels in this classical genetic obesity syndrome.

\section{SUBJECTS AND METHODS}

Each subject was recruited and consented from a larger survey on genotype/phenotype correlations in PWS and was fasted overnight before blood samples collected and plasma separated..$^{32}$ Peripheral blood was collected in EDTA tubes following informed consent. Twenty-eight subjects with PWS (13 females, 15 males; mean ages $\pm \mathrm{SD}=24.6 \pm 11.6$ years; age range $=6$ to 48 years; mean body mass index $(\mathrm{BMI})=35.9 \pm$ 11.9 ) and 22 non-syndromic subjects with obesity of unknown cause ( 16 females, 6 males; mean age $\pm \mathrm{SD}=32.7 \pm 12.5$ years; age range $=8$ to 50 years; mean $\mathrm{BMI}=34.6 \pm 5.9$ ) were selected for comparison. All subjects were examined by one of us (MGB) and the clinical diagnosis of PWS made and confirmed by genetic testing (e.g., chromosome studies with fluorescence in situ hybridization, DNA methylation and chromosome 15qll-q13 microsatellite analysis); whereas, the subjects with obesity were non-syndromic and had normal genetic testing. Obesity was defined as a BMI of 30 for adults 18 years of age) and a BMI $>95$ th percentile using published standards for sex and age for subjects $<18$ years. ${ }^{33}$

All subjects had extensive endocrine studies including plasma insulin, glucose, C-peptide, cortisol, sex hormone, thyroid and leptin levels. Statistical analyses for all subjects included comparisons of group means by Student's $t$-test, Pearsonian correlation coefficients and one way ANOVA (Tukey) tests utilizing the SPSS computer software package. ${ }^{34}$ Seventeen subjects with PWS had a 15qll-q13 deletion, 10 were found to have maternal disomy 15 (both 15 s from the mother) and two had an imprinting defect. Both groups of subjects were similarly matched for IQ (both subject groups had IQs in the mild retardation range) and had comparable obesity status. No patient was treated with growth or other hormones. For comparison purposes, normative laboratory data were used from 100 healthy adult volunteers available from the commercial company supplying the CRP assay kits (Diagnostic Products Corporation, Los Angeles, CA). Height to the nearest $0.1 \mathrm{~cm}$, weight to the nearest $0.1 \mathrm{~kg}, \mathrm{BMI}\left(\mathrm{kg} / \mathrm{m}^{2}\right)$ and waist-to-hip ratio (waist at umbilicus level measured to the nearest $0.1 \mathrm{~cm}$ and hip at greater trochanter level measured to the nearest 0.1 $\mathrm{cm}$ ) were obtained routinely on each subject in the clinical setting. DEXA or dual energy x-ray absorptiometry utilizing the Model DPX system from Lunar Corporation, (Madison, WI.) was performed routinely to determine body composition (percentage of fat and lean body mass) while the subject was in supine position as previously described. ${ }^{27}$ The demographic, anthropometric and body composition data are shown in Table 1.

A solid-phase, chemiluminescent immunometric assay (Immulite 2000 High Sensitivity CRP; Diagnostic Products Corporation, Los Angeles, CA) for quantitative measurement of C-reactive protein (CRP) was performed following manufacturer's protocols. The kit was standardized by the commercial company using quality control samples from at least 100 healthy adult volunteers with repeated measures. The antibody used was highly specific for CRP with no detectable percent cross-reactivity with human albumin, IgG or transferrin and had a high precision with coefficient of variations ranging from 3.1 to $8.7 \%$ in quadruplicate assays performed over the course of several days. 
Table 1

Age, sex, C-reactive protein (CRP) and anthropometric data in subjects with Prader-Willi syndrome or obesity

\begin{tabular}{|c|c|c|c|c|c|c|c|c|c|c|}
\hline Group & $\mathrm{N}$ & Sex M:F & $\begin{array}{l}\text { Age range } \\
(\mathrm{yr})\end{array}$ & $\begin{array}{l}\text { Average age } \\
\text { (yr) }\end{array}$ & $\begin{array}{l}\text { Average height }{ }^{b} \\
\qquad(\mathrm{~cm})\end{array}$ & $\begin{array}{l}\text { Average weight } \\
(\mathrm{kg})\end{array}$ & $\begin{array}{l}\text { Average Waist-to-Hip } \\
\text { ratio }\end{array}$ & $\begin{array}{l}\text { Average BMI } \\
\left(\mathrm{kg} / \mathrm{m}^{2}\right)\end{array}$ & $\begin{array}{l}\text { Average } \% \text { Fat }^{a} \\
\quad \text { (DEXA) }\end{array}$ & $\begin{array}{c}\text { Average CRP } \\
(\mathrm{mg} / \mathrm{L})\end{array}$ \\
\hline PWS & 28 & $15: 13$ & $6-48$ & $24.6 \pm 11.6$ & $152.1 \pm 8.8$ & $81.3 \pm 23.9$ & $0.99 \pm 0.12$ & $35.9 \pm$ & $49.3 \pm 8.9$ & 10.3 \\
\hline Obese & 22 & $6: 16$ & $8-50$ & $32.3 \pm 12.2$ & $162.2 \pm 9.8$ & $98.2 \pm 38.9$ & $0.96 \pm 0.07$ & $36.6 \pm 10.7$ & $43.9 \pm 7.4$ & $8.8 \pm 10.9$ \\
\hline
\end{tabular}

${ }^{a} P<0.05$ ( $t$ test $),{ }^{b} P<0.001$ ( $t$ test $)$.

\section{RESULTS AND DISCUSSION}

Plasma concentration of CRP is an aid in the detection and evaluation of infection, tissue injury, inflammatory disorders and associated diseases. We measured plasma CRP levels between subjects with PWS and obese subjects and compared with normative laboratory data. Table 2 shows correlation data for anthropometric, body composition and CRP data from subjects with PWS and obesity. The average CRP level in the 28 subjects with PWS was $10.3 \pm 8.8 \mathrm{mg} / \mathrm{L} ; 8.8 \pm 10.9 \mathrm{mg} / \mathrm{L}$ for 22 obese comparison subjects; and $2.6 \pm 3.0 \mathrm{mg} / \mathrm{L}$ for 100 healthy adults analyzed by the commercial laboratory supplying the CRP kits. To assist health-care providers in selecting and using biomarkers to monitor for inflammation and/or cardiovascular disease, the American Hearth Association (AHA) and Centers for Disease Control (CDC) proposed a joint scientific statement for the use of CRP levels in the clinical setting based on clinical evidence. ${ }^{35}$ Three relative risk categories were proposed for CRP levels (low $<1 \mathrm{mg} / \mathrm{L}$; average 1.0 to $3.0 \mathrm{mg} / \mathrm{L}$ and high $>3.0 \mathrm{mg} / \mathrm{L}$ ). The three categorical classes corresponded to approximate tertile rankings in the adult population. The high risk tertile $(>3.0 \mathrm{mg} / \mathrm{L})$ had an approximate two-fold increase in relative risk compared to the low risk tertile $(1 \mathrm{mg} / \mathrm{L})$.

Figure 1 shows the distribution of the CRP data for the three groups (PWS, obese and healthy adults). The plasma CRP distribution in the normative healthy adults showed reduced variation and lower mean levels compared with our two subject groups (obese and PWS). Thirteen of 22 obese subjects and 20 of 28 subjects with PWS had CRP levels $>3.0 \mathrm{mg} / \mathrm{L}$. This compares with 30 of 100 healthy adults analyzed by the commercial company with CRP levels $>3.0 \mathrm{mg} / \mathrm{L}$.

Table 2

Correlation data for $\mathrm{C}$-reactive protein (CRP) and other variables in subjects with Prader-Willi syndrome or obesity

\begin{tabular}{lcccccc}
\hline & \multicolumn{2}{c}{$\begin{array}{c}\text { Prader-Willi } \\
\text { syndrome subjects }\end{array}$} & & \multicolumn{2}{c}{ Obese subjects } \\
\cline { 2 - 3 } \cline { 6 - 7 } Variables & Correlation & $P$-value & & Correlation & $P$-value \\
\cline { 1 - 3 } Age vs. CRP & -0.18 & 0.37 & & 0.22 & 0.37 \\
BMI vs. CRP & 0.01 & 0.98 & & 0.28 & 0.22 \\
Weight vs. CRP & 0.35 & 0.11 & & 0.21 & 0.40 \\
Waist-to-hip ratio vs. CRP & -0.20 & 0.45 & & 0.05 & 0.86 \\
\% fat vs. CRP & -0.05 & 0.82 & & -0.09 & 0.73 \\
\hline
\end{tabular}

${ }^{a}$ All $P$ values are not significant.
No significant difference was seen in fasting plasma CRP levels in the PWS and obese subjects. However, there was a significantly lower CRP level seen in the 100 healthy adults compared with either subject group (PWS or obese). The average CRP levels observed in both the PWS and obese subject groups would be categorized as high $(>3.0 \mathrm{mg} / \mathrm{L})$ while the average CRP level seen in the healthy adults would be categorized as average ( 1.0 to $3.0 \mathrm{mg} / \mathrm{L}){ }^{35}$

No significant difference was seen in the average CRP levels in either males or females from either of the two subject groups (obese or PWS) or between those individuals younger or older than 18 years of age (Table 3 ). Three of our 22 obese subjects and 9 of our 28 subjects with PWS were younger than 18 years. There were no significant effects (i.e., significant positive or negative correlations (data not shown) observed for genetic subtypes (15qll-q13 deletion or maternal disomy 15) and CRP concentrations which is consistent with our previous report of adiponectin levels in PWS. ${ }^{29}$ Additionally, we saw no significant correlations between CRP levels for body mass index (BMI), percentage of fat, weight, age, or waist to hip ratios (see Table 2).

As elevated CRP values are associated with pathologic changes, the CRP assay may provide useful information for the diagnosis, treatment and monitoring of inflammatory conditions and associated diseases. ${ }^{36-38}$ Body weight and obesity status are consistently associated with an elevated CRP level and weight loss associated with a reduction in CRP levels. ${ }^{10-12}$ Several factors are known to be associated with an elevated CRP level besides chronic infections or inflammations, obesity and hypertension such as cigarette smoking, low HDL/high triglyceride levels and estrogen/progesterone hormone use. ${ }^{35}$

Sixty percent of our obese subjects (mean age $=35.4$ years; age range $=19-50$ years) and $71 \%$ of our subjects with PWS (mean age $=25.5$ years; age range $=6-48$ years) had CRP levels in the elevated risk category (CRP $>3.0 \mathrm{mg} / \mathrm{L}$ ). This compared with $30 \%$ for the 100 healthy adults (age range $=$ 18-60 years). Chi-square $2 \times 2$ tests were used to analyze the proportion of individuals in the high risk category (CRP levels $>3.0 \mathrm{mg} / \mathrm{L}$ ) and significant differences were found when comparing our obese subjects with healthy adults $(P<0.01)$ and our subjects with PWS with healthy adults $(P<0.001)$. However, no significant difference was found when subjects with PWS were compared with obese subjects. As indicated, the average CRP level in both of our obese and PWS groups fell within the high risk category while the average CRP level in the healthy adults was placed in the average risk category. Thus, the 


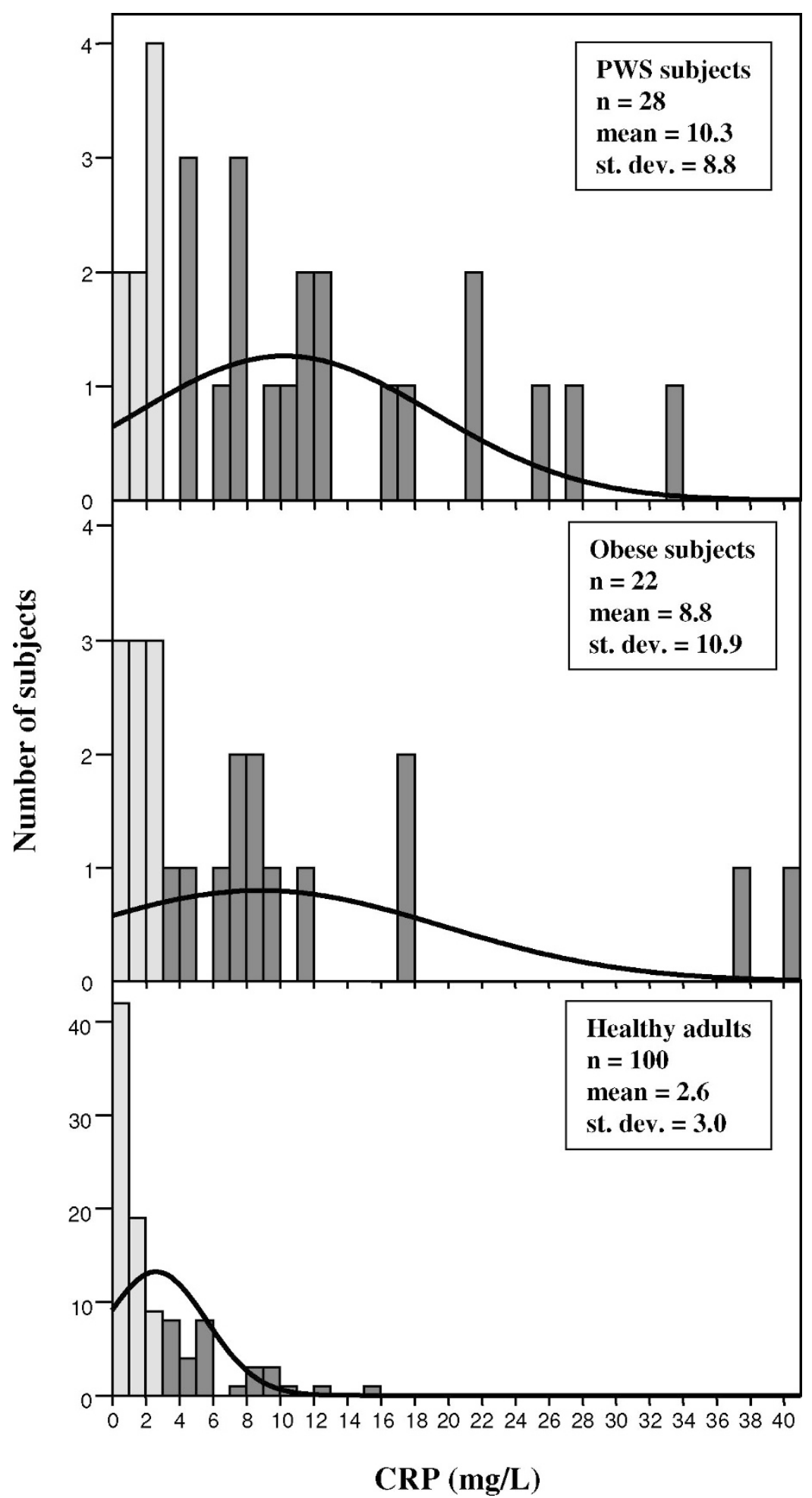

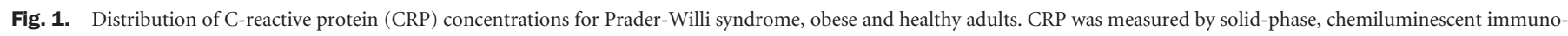

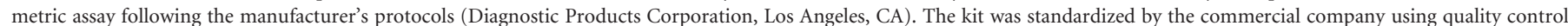
samples from 100 healthy adult volunteers (distribution shown in bottom panel). Darker bars represent elevated CRP levels ( $\geq 3 \mathrm{mg} / \mathrm{L}$ ).

CRP levels seen in our subjects with PWS were comparable to levels obtained for our obese subjects but significantly higher than in the healthy adults analyzed by the commercial company supplying the CRP kits.
The best evidence to date supports the use of monitoring CRP levels as an independent predictor of increased coronary risk. ${ }^{35}$ The optimal use of screening CRP levels is to identify patients without known cardiovascular disease (which repre- 
Table 3

Comparison of C-reactive protein (CRP) data between males and females and individuals greater or less than 18 years for each subject group

\begin{tabular}{|c|c|c|c|c|c|}
\hline \multirow[b]{2}{*}{ Category } & \multirow[b]{2}{*}{ Subject group } & \multirow[b]{2}{*}{$\mathrm{N}$} & \multicolumn{2}{|c|}{$\mathrm{CRP}(\mathrm{mg} / \mathrm{L})$} & \multirow[b]{2}{*}{$t$-test ${ }^{a}$} \\
\hline & & & Mean & SD & \\
\hline \multirow[t]{2}{*}{ Males } & Obese & 6 & 7.40 & 5.93 & \\
\hline & PWS & 15 & 8.89 & 7.20 & 0.66 \\
\hline \multirow[t]{2}{*}{ Females } & Obese & 16 & 9.33 & 12.44 & \\
\hline & PWS & 13 & 11.83 & 10.51 & 0.57 \\
\hline \multirow[t]{2}{*}{ Younger than 18 years } & Obese & 3 & 0.96 & 0.64 & \\
\hline & PWS & 9 & 8.57 & 10.03 & 0.23 \\
\hline \multirow[t]{2}{*}{ Older than 18 years } & Obese & 19 & 10.04 & 11.30 & \\
\hline & PWS & 19 & 11.05 & 8.40 & 0.76 \\
\hline
\end{tabular}

${ }^{a} t$-test results between the two groups in each row (none were significant).

sents most subjects with PWS who may be at a higher absolute risk than estimated by the analysis of major risk factors. Those patients at an intermediate risk (e.g., $10 \%$ to $20 \%$ risk for coronary heart disease over 10 years) in which the physician needs additional information to guide medical evaluation and management including the use of imaging, exercise testing or therapies such as lipid lowering or antiplatelet drugs may be benefited from CRP measurements. ${ }^{35}$ Those patients with high risk factors for cardiovascular disease such as obesity, hypertension or hypertriglyceridemia should qualify for medical interventions or assessments. Possibly, the use of CRP measures may further motivate some patients with moderate to high risk levels to improve their lifestyles including dietary modifications, exercise, weight loss, or smoking cessation or to comply with drug therapies.

It appears that the finding of increased CRP levels in subjects with PWS is not surprising but does not place them at a higher cardiovascular risk compared to obese comparison subjects. For example, in a large prospective study and meta-analysis of elevated CRP levels in the general population, an increased risk was present but with a relatively modest odd ratio of 1.5.9 However, the findings on CRP alone are not sufficient to make any conclusions with so many other factors influencing cardiovascular risk such as clinical and laboratory data (e.g., triglycerides, cholesterol fractions, total cholesterol to HDL cholesterol ratios), family history and hypertension. Additional research is needed to further study the role of elevated CRP levels in both males and females with PWS and studies on the natural history of this syndrome. As the subjects in our study did not present with known heart disease, diabetes mellitus or other hormone disturbances, the elevated CRP levels may represent subclinical inflammation and a potential risk for type 2 diabetes or cardio-peripheral vascular disease. Assessment of other risk factors and long term follow-up studies are needed to further relate these observations in subjects with PraderWilli syndrome and allow their incorporation into therapeutic interventions to improve clinical outcomes.

\section{References}

1. Tillet W, Francis T. Serologic reactions in pneumonia with a non-protein somatic fraction of pneumococcus. J Exp Med 1930;52:561-571.

2. Abernathy TJ, Avery OT. The occurrence during acute infections of a protein not normally present in the blood. I. Distribution of the reactive protein in patient's sera and the effect of calcium on the flocculation reaction with C-polysaccharide of pneumococcus. J Exp Med 1941;73:173-182.

3. Schultz Dr. Arnold PI. Properties of four acute phases proteins: CRP, serum amyloid A protein, -acid glycoprotein, and fibrinogen. Semin Arthritis Rheum 1990;20:129_ 147.

4. Osmand AP, Friedeson B, Gewurz H, Painter RH, et al. Characterization of C-reactive protein and the complement subcomponent Clt as homologous proteins displaying cyclic pentameric symmetry (pentraxins). Proc Nat Acad Sci USA 1977;74: 739-743.

5. Tietz NW editor. Clinical guide to Laboratory Tests. 3rd ed. Philadelphia: WB Saunders, 1995:358.

6. Ridker PM, Cushman M, Stampfer MJ, Tracy RP, et al. Inflammation, aspirin, and the risk of cardiovascular disease in apparently healthy men. NEngl J Med 1997;336: 973-979.

7. Ridker PM, Hennekens CH, Buring JE, Rifai N. C-reactive protein and other markers of inflammation in the prediction of cardiovascular disease in women. $N$ Engl J Med 2000;342:836-843.

8. Hackam DG, Anand SS. Emerging risk factors for atherosclerotic vascular disease: a critical review of the evidence. JAMA 2003;290:932-940.

9. Oanesh J, Wheeler JG, Hirschfield GM, Eda S, et al. C-reactive protein and other circulating markers of inflammation in the prediction of coronary heart disease. N Engl J Med 2004;350:1387-1397.

10. Visser M, Bouter LM, McQuillan GM, Wener MH, et al. Elevated C-reactive protein levels in overweight and obese adults. JAMA 1999;282:2131-2135.

11. Tchernof A, Nolan A, Sites CK, Ades PA, et al. Weight loss reduces C-reactive protein levels in obese postmenopausal women. Circulation 2002;105:564-569.

12. Ziccardi P, Nappo F, Giugliano G, Esposito K, et al. Reduction of inflammatory cytokine concentrations and improvement of endothelial functions in obese women after weight loss over one year. Circulation 2002;105:804-809.

13. MacGregor AJ, Gallimore JR, Spector TO, Pepys MB. Genetic effects on baseline values of C-reactive protein and serum amyloid A protein: a comparison of monozygotic and dizygotic twins. Clin Chem 2004;50:130-134.

14. Carlson CS, Aldred SF, Lee PK, Tracy RP, et al. Polymorphisms within the C-reactive protein (CRP) promoter region are associated with plasma CRP levels. Am J Hum Genet 2005;77:64-77.

15. Butler MG. Prader-Willi syndrome: current understanding of cause and diagnosis. Am J Med Genet 1990;35:319-332.

16. Cassidy SB, Oykens E, Williams CA. Prader-Willi and Angelman syndromes: sister imprinted disorders. Am J Med Genet 2000;97:136-146.

17. Cassidy SB, Schwartz S. Prader-Willi Syndrome. GeneReviews 2005; http://www. genereviews.org.

18. Bittel DC, Butler MG. Prader-Willi syndrome: clinical genetics, cytogenetics and molecular biology. Expert Rev Mol Med 2005;7:1-20.

19. Nicholls RD, Knoll JH, Butler MG, Karam S, et al. Genetic imprinting suggested by maternal heterodisomy in nondeletion Prader-Willi syndrome. Nature 1989;342: 281-285.

20. Lamb AS, Johnson WM. Premature coronary artery atherosclerosis in a patient with Prader-Willi syndrome. Am J Med Genet 1987;28:873-880.

21. Page SR, Nussey SS, Haywood GA, Jenkins JS. Premature coronary artery disease and the Prader- Willi syndrome. Postgrad Med J 1990;66:232-234.

22. Eiholzer U. Prader-Willi syndrome: effects of human growth hormone treatment. In: Savage, MO. ed. Endocrine Development Series, Vol. 3, 2001: Basil, Switzerland: Karger.

23. Kuromaru R, Kohno H, Ueyama N, Hassan HM, et al. Long-term prospective study of body composition and lipid profiles during and after growth hormone $(\mathrm{GH})$ treatment in children with GH deficiency: Gender-specific metabolic effects. J Clin Endocrinol Metab 1998;83:3890-3896.

24. L' Allemand D, Schlumpf M, Torresani T, Girard J. Insulin secretion before and under 3 years of growth hormone (GH) therapy in Prader- Willi syndrome (PWS) (abstract). Exp Clin Endocrinol Diabetes 2000;108:127.

25. Ruvalcaba RH, Holm V. Effects of growth hormone in Prader-Willi syndrome. A case report. Clin Pediatr 1993;32:292-295.

26. Goldstone AP, Thomas EL, Brynes AE, Bell JD, et al. Visceral adipose tissue and metabolic complications of obesity are reduced in Prader-Willi syndrome female adults: evidence for novel influences on body fat distribution. J Clin Endocrinol Metab 2001;86(9):4330-4338.

27. Talebizadeh Z, Butler MG. Insulin resistance and obesity-related factors in PraderWilli syndrome: comparison with obese subjects. Clin Genet 2005;67:230-239. 


\section{Butler et al.}

28. Hoybye C, Bruun IM, Richelsen B, Flyvbjerg A, et al. Serum adiponectin levels in adults with Prader-Willi syndrome are independent of anthropometrical parameters and do not change with GH treatment. Eur J Endocrinol 2004;151:457-461.

29. Kennedy L, Bittel DC, Kibiryeva N, Kalra SP, et al. Circulating adiponectin levels, body composition and obesity-related variables in Prader-Willi syndrome: Comparison with obese subjects. Int J Obes 2005; Advance online publication: 4 October, 2005.

30. Jewell WS, Marnell LL, Rokeach LA, Du Clos TW. C-reactive protein (CRP) binding to the Sm-D protein of snRNPS. Identification of a short polypeptide binding region. Mol Immunol 1993;30:701-708.

31. Pepys MB, Booth SE, Tennent GA, Butler PJ, et al. Binding of pentraxins to different nuclear structures: C-reactive protein binds to small nuclear ribonucleoprotein particles, serum amyloid P component binds to chromatin and nucleoli. Clin Exp Immunol 1994;97:152-157.
32. Thompson T, Butler MG. Prader-Willi syndrome. Clinical, behavioral and genetic findings. In:Wolraich, ML ed. Disorders of Development and Learning, 3rd Edition 2003: Hamilton, Canada: B.C. Decker, Inc.

33. Kuczmarski RJ, Ogden CL, Grummer-Strawn LM, Flegal KM, et al. CDC growth charts: United States. Adv Data 2002;8:1-27.

34. SPSS Inc. SPSS Statistical Software System, Version 10.1. IL: Chicago, 2000.

35. Pearson T, Mensah G, Alexander RW, Anderson JL, et al. Markers of inflammation and cardiovascular disease. Circulation 2003;107:499-511.

36. Dixon JS, Bird HA, Sitton NG, Pickup ME, et al. CRP in the serial assessment of disease activity in rheumatoid arthritis. Scand J Rheumatol 1984;13:39-44.

37. Hind CR, Pepys MB. The role of CRP measurement in clinical practice. Int Med 1984;5:112-151.

38. van Leeuwen MA, van Rijswijk MH. Acute phase proteins in the monitoring of inflammatory disorders. Baillieres Clin Rheumatol 1994;8:531-552. 